\title{
Lifestyles and health risks of university students
}

\author{
Guillermina Arenas ${ }^{1,}{ }^{*}$, Ariel Ramírez ${ }^{2}$ \\ ${ }^{1}$ Degree in nursing, FES-Iztacala, National Autonomous University of Mexico, Mexico State, Mexico. \\ 2 Degree in nursing, FES-Iztacala, National Autonomous University of Mexico, Mexico State, Mexico.
}

Publication history: Received on 13 December 2020; revised on 21 December 2020; accepted on 24 December 2020

Article DOI: https://doi.org/10.30574/gscarr.2020.5.3.0125

\begin{abstract}
Introduction: University life represents an important change in students' development; since they enter adulthood, in which they will deal with academic challenges and responsibilities; reducing considerably the time to carry out physical, recreational and/or cultural activities; favoring diseases related to overweight and obesity, because of sedentarism, potentializing the consumption of harmful substances as relaxation or anti-stress mechanisms. Objective: To analyze the variables in the consumption of tobacco, alcohol, physical and cultural activity in new students in the years 2016, 2017 and 2018. Materials and methods: Comparative, observational study with a descriptive scope. It was conducted by non-probabilistic sampling at convenience, in three generations, 2016, 2017 and 2018. The variables, alcohol consumption, tobacco consumption, frequency of physical activity and frequency of cultural activities were evaluated. Results and conclusions: Of the three generations evaluated, the one with the highest average for the four variables to be evaluated was 2017. The practice of cultural activities is the least performed in the three generations. The analysis of alcohol and tobacco consumption, as well as physical activity, is consistent with the data reported in ENSANUT 2016, 2018, and ENCODAT 2017.
\end{abstract}

Keywords: Life style; Alcoholism; Tobacco-Derived Products Packing; Student Health Services; Culture; Student

\section{Introduction}

The World Health Organization defines a risk factor as "any trait, characteristic or exposure of an individual that increases his or her probability of suffering a disease or injury", and also highlights tobacco and alcohol consumption among the most important risks that predispose the population to suffer from a disease. However, some factors such as hypertension or obesity, are totally preventable if you have a healthy lifestyle. By lifestyle we understand all those behaviors, habits and practices that can be risky to health. [1]

Various studies have shown that academic performance is not only dependent on intellectual capacity, but also needs confidence, favorable expectations, economy and lifestyles, which favor a healthy environment for learning. When exposed to the academic demands of daily life in the university, students put their performance at risk when they distrust their capacities and potentialities; such stress scenarios favor the consumption of substances that harm their health, favored when students stop recreational activities [2,3].

University students during this stage suffer changes in their lifestyle and it is important to emphasize physical activity; scientific studies have proven that regular physical activity provides health benefits as well as physiological, psychological and social benefits. The lack of physical activity is one of the problems of today's society, which becomes more evident during the university stage, since it brings with its health problems such as overweight and obesity [4]

\footnotetext{
${ }^{*}$ Corresponding author: Guillermina Arenas

Degree in nursing, FES-Iztacala, National Autonomous University of Mexico, Mexico State, Mexico.
} 
[5]. University students, whose ages range from 17 to 26 years old, are a population that is unprotected in terms of health problems and needs, since they are insufficiently attended to by public and internal university policies, where the lack of activities at the first level of prevention stands out. It is worth highlighting some diseases suffered by young people at this age, such as obesity, metabolic syndrome, dyslipidemias, hyperglycemia and/or insulin resistance, which, since they are not attended to in a concrete and continuous manner, tend to evolve as the student body grows, until reaching complications such as DM2 and cardiovascular diseases, which occupy the first places of morbimortality in Mexico [6-8]

In the transition from the upper middle school stage to the university stage, there is a decrease in vigorous physical activity that requires a great deal of effort, causing rapid breathing and increasing heart rate (approximately $<6$ Metabolic Equivalent of Task; METS) as opposed to moderate activity that significantly accelerates heart rate (approximately 3-6 METS); can be justified by the disappearance of physical education classes that met the WHO's healthy recommendations that adults 18-64 years of age engage in 30 minutes of moderate or vigorous physical activity daily, which is less than the 60 minutes recommended for children and adolescents. In addition, several studies consider physical activity to be a protective factor against negative habits such as alcohol, drugs or tobacco.

According to the National Survey on Drug, Alcohol and Tobacco Consumption (ENCODAT 2016-2017), alcohol consumption in the general population has decreased by two percentage points, from 51.4\% in 2011 to $49.1 \%$ in 2016 . By sex, the prevalence of those who have ever consumed alcohol in men shows percentages of $80.6 \%$ to $80.1 \%$ in 2011 and 2016 respectively. The situation in women, the prevalence of those who have "ever consumed", remains at $62.6 \%$ in both 2011 and 2016 [9].

ENCODAT in relation to drug consumption has been increasing significantly between 2011 and 2016 in the general population, with respect to the consumption of any drug, illegal drugs and marijuana, going from $7.8 \%, 7.2 \%$ and $6 \%$ to $10.3 \%, 9.9 \%$ and $8.6 \%$ respectively. In relation to sex, in men the consumption of any drug increased from $13 \%$ to $16.2 \%$, illegal drugs from $12.5 \%$ to $15.8 \%$ and marijuana from $10.6 \%$ to $14 \%$. In women there is an increase in consumption of any drug from $3 \%$ to $4.8 \%$, illegal drugs from $2.3 \%$ to $4.3 \%$ and marijuana from $1.6 \%$ to $3.7 \%$ in 2011 and 2016 respectively. Drug dependence is reported by $0.6 \%$ of the population, $1.1 \%$ in men and $0.2 \%$ in women between 18 and 34 years of age [9].

Regarding tobacco, Mexico has approximately 85.2 million inhabitants between 12 and 65 years of age, of which ENCODAT 2016-2017 reports that 14.9 million Mexicans are current smokers (3.8 million women (8.7\%), 11.1 million men (27.1\%) of which 5.4 million smoke daily (6.4\%) and 9.4 million smoke occasionally (11.1\%) [9].

The UNAM, through its various institutions, offers a wide variety of cultural and sports activities, in which students have great privileges, as they enjoy great discounts, and can even access artistic workshops, sports equipment and personalized holistic attention completely free. However, there are two situations that we can observe in the university population The first has to do with the little attachment that exists to the little cultural consumption, as mentioned by Molina, Casillas, Colorado and Ortega in their Survey of Cultural Consumption of University Students (2012), where they described that more than $50 \%$ of the students of the University of Veracruz, "never" or "almost never" have attended activities, musical, theatrical or dance, organized by their own institution; which reflects a university society with low consumption of cultural activities. On the other hand, the few university students who do have the habit of practicing or attending such activities, are reduced in time due to their homework and school obligations, and are forced to reduce the time dedicated or even abandon their cultural activities altogether. The same applies to sports activities, since the more you advance in your academic formation, the less time you will dedicate to the practice of some sport [10-12]. In this sense, the FES-Iztacala, UNAM; has as a necessity the integral evaluation of its new students; this evaluation allows us to recognize the risk factors to which our new population is exposed, at the same time it allows us to identify protective factors that benefit their health. Due to the above, this article shows a comparative analysis of new students from three different school generations.

\section{Material and methods}

Based on Supo's taxonomy (2012), this is a comparative, analytical, observational study with a descriptive scope.

To carry out the study, data was taken from new students at FES-Iztacala, UNAM; from the six careers taught in the faculty (Medicine, Nursing, Optometry, Dentistry, Biology and Psychology), who attended the Automated Medical Examination, having a final population of 141 students for the year 2016 population, 249 for the 2017 generation and 177 for the 2018 generation. The assessment instrument consisted of four dimensions, alcohol consumption, tobacco consumption, physical activity and cultural activity, with which the frequency and quantity of consumption was 
measured. Before the delivery of the instruments, the students were explained the objective of the study and were given informed consent before the beginning of the assessment.

The young people of new entry had an average age of 18 years old, between men and women, the measurement instrument served as part of the comprehensive health assessment. To give reliability to the data obtained, internal validation tests were carried out (Supo 2012) for documentary instruments.

The statistical analysis plan was carried out with the SPSS version 22 program, first the distribution of the variables was determined, later the Levene Test was used to evaluate the equality of variances and to be able to determine if it was viable to carry out a comparison of means. For the comparison of data among the three generations, as well as in the six races, the ANOVA and post hoc Tukey Test was used. For the comparison between genders, the Student T-test was used for independent samples. For data description, graphs with mean and standard error were used. An alpha significance level of 0.05 was established.

\section{Results}

The results shown below are only those that have statistical significance equal to or less than 0.05 . These results are the result of the application of an instrument to a total of 458 new students of FES-Iztacala, who attended the Automated Medical Examination (AME), of the generations 2016, 2017 and 2018, of the careers of Nursing, Biology, Medicine, Optometry, Dentistry and Psychology.

Table 1 shows the data disaggregated by sex in each generation that participated in the exam, in which the most abundant population was women in 2016 and 2017, the opposite case in 2018, where the population with the highest number of attendees was men.

Table 1 Data disaggregated by sex of participants

\begin{tabular}{|l|l|l|l|l|l|}
\hline \multicolumn{2}{|c|}{} & \multicolumn{2}{|l|}{ Generation } & \multirow{2}{*}{ Total } \\
\cline { 3 - 7 } \multicolumn{2}{c|}{} & 2016 & 2017 & 2018 & \\
\hline \multirow{3}{*}{ Student sex } & Mens & 63 & 72 & 125 & 260 \\
\cline { 2 - 6 } & Women & 138 & 177 & 52 & 367 \\
\cline { 2 - 6 } & Total & 201 & 249 & 177 & 627 \\
\hline
\end{tabular}

Table 2 shows the data disaggregated by career. Students in the careers of Medical Surgeon, Psychology and Nursing, were the ones who mostly applied to the EMA, while the career of Biology was the one in which less students participated in the three years that the assessment was made.

Table 2 Disaggregated data by race

\begin{tabular}{|l|l|l|l|l|l|l|l|}
\hline & \multicolumn{3}{|l|}{$\mathbf{2 0 1 6}$} & \multicolumn{2}{l}{$\mathbf{2 0 1 7}$} & $\mathbf{2 0 1 8}$ & P Value \\
\hline & Mean & DE & Mean & DE & Mean & DE & \\
\hline Age & 18.55 & 1.77 & 21.18 & 1.95 & 21.2 & 2.07 & 0.000 \\
\hline Tobacco Frequency & 1.95 & 1.28 & 4.62 & 1.92 & 2.59 & 2.37 & 0.000 \\
\hline Alcohol Frequency & 0.97 & 0.93 & 3.13 & 1.31 & 2.63 & 1.39 & 0.000 \\
\hline Physical activity frequency & 1.22 & 1.27 & 4.92 & 2.49 & 2.98 & 2.47 & 0.000 \\
\hline Cultural activity frequency & 0.99 & 0.88 & 5.67 & 1.82 & 1.5 & 1.18 & 0.000 \\
\hline
\end{tabular}


This table shows the mean values and standard deviations of age, frequency of tobacco and alcohol consumption and frequency of physical and cultural activity. New students in 2016 were the only generation to have the average age corresponding to the national entrance age to higher education, while students entering in 2017 and 2018 are 3 years behind. With respect to the frequency of tobacco consumption, the students in 2017 are the ones who reported the highest average consumption. After taking Tukey's test, it was observed that 2016 is significant compared to 2017, while 2017 has a statistical difference with 2016 and 2018. These results are similar to those reported in ENCODAT 20162017, where it is indicated that in the period 2009-2015 the increase in consumption was not significant; however, since the last date and until 2017, the behavior of the data shows considerable increases, as shown in Table 3.

Table 3 Tukey dependent test of tobacco and alcohol consumption variables

\begin{tabular}{|c|c|c|c|}
\hline \multicolumn{2}{|c|}{ Generation } & \multirow{2}{*}{$\begin{array}{l}\text { Typical } \\
\text { Error }\end{array}$} & \multirow[b]{2}{*}{ Sig. } \\
\hline \multicolumn{2}{|c|}{ Tobacco Frequency } & & \\
\hline \multirow{2}{*}{2016} & 2017 & 0.2869 & 0.000 \\
\hline & 2018 & 0.29919 & 0.285 \\
\hline \multirow{2}{*}{2017} & 2016 & 0.2869 & 0.000 \\
\hline & 2018 & 0.21147 & 0.000 \\
\hline \multirow{2}{*}{2018} & 2016 & 0.29919 & 0.285 \\
\hline & 2017 & 0.21147 & 0.000 \\
\hline \multicolumn{2}{|c|}{ Generation } & \multirow{2}{*}{$\begin{array}{l}\text { Typical } \\
\text { Error }\end{array}$} & \multirow[b]{2}{*}{ Sig. } \\
\hline \multicolumn{2}{|c|}{ Alcohol Frequency } & & \\
\hline \multirow{2}{*}{2016} & 2017 & 0.10165 & 0.000 \\
\hline & 2018 & 0.1094 & 0.000 \\
\hline \multirow{2}{*}{2017} & 2016 & 0.10165 & 0.000 \\
\hline & 2018 & 0.10951 & 0.000 \\
\hline \multirow{2}{*}{2018} & 2016 & 0.1094 & 0.000 \\
\hline & 2017 & 0.10951 & 0.000 \\
\hline
\end{tabular}

At this point of the evaluation, no significant differences were found between the consumption of tobacco among men and women in any of the three generations; ENCODAT reports that $17 \%$ of the Mexican population between the ages of 12 and 65 currently smokes, and that of this percentage $8.7 \%$ are women and $27.1 \%$ are men. Nevertheless, it is important to note that the average age of tobacco use is 21 for women and 18.8 for men, so it can be seen that when students enter university, the great majority of them already have a smoking habit. With respect to alcohol consumption, statistical significance was obtained by comparing the averages of the three years, with the year 2017 being the one that reported the highest frequency of consumption. The analysis with the Tukey Post Hoc Test, statistical significance was obtained in the alcohol consumption of the three generations, this increase with respect to 2016 to 2017 coincides with those reported with ENCODAT, which indicates a percentage decrease, between the period of 2011 to 2015 . However, by 2017 , the increase was significant, going from $31.6 \%$ to $35.9 \%$. 
Table 4 Tukey dependent test of physical activity and cultural activity variables

\begin{tabular}{|c|c|c|c|}
\hline \multicolumn{2}{|c|}{ Generation } & \multirow{2}{*}{$\begin{array}{l}\text { Typical } \\
\text { Error }\end{array}$} & \multirow[b]{2}{*}{ Sig. } \\
\hline \multicolumn{2}{|c|}{$\begin{array}{l}\text { Physical } \\
\text { frequency }\end{array}$} & & \\
\hline \multirow{2}{*}{2016} & 2017 & 0.20567 & 0.000 \\
\hline & 2018 & 0.22362 & 0.000 \\
\hline \multirow{2}{*}{2017} & 2016 & 0.20567 & 0.000 \\
\hline & 2018 & 0.21354 & 0.000 \\
\hline \multirow{2}{*}{2018} & 2016 & 0.22362 & 0.000 \\
\hline & 2017 & 0.21354 & 0.000 \\
\hline \multicolumn{2}{|c|}{ Generation } & \multirow{2}{*}{$\begin{array}{l}\text { Typical } \\
\text { Error }\end{array}$} & \multirow[b]{2}{*}{ Sig. } \\
\hline \multicolumn{2}{|c|}{ Cultural activity frequency } & & \\
\hline \multirow{2}{*}{2016} & 2017 & 0.13088 & 0.000 \\
\hline & 2018 & 0.14099 & 0.084 \\
\hline \multirow{2}{*}{2017} & 2016 & 0.13088 & 0.000 \\
\hline & 2018 & 0.13794 & 0.000 \\
\hline \multirow{2}{*}{2018} & 2016 & 0.14099 & 0.084 \\
\hline & 2017 & 0.13794 & 0.000 \\
\hline
\end{tabular}

The values of Tukey's physical activity test and the frequency of cultural activity for students assessed in the 2016, 2017, and 2018 EMA are represented in Table 6. Data from all three years show statistical significance for physical activity frequency. Data for students in all three years show statistical significance in terms of physical activity frequency.

\section{Discussion}

The average age recorded in the automated tests was increasing from an average of 18 to 21 years old, this data is consistent with those reported with the University Statistics Portal. Zorilla has reported that this phenomenon is seen more in the students who take the university selection exam; unfortunately, young people are not followed up on. $[13,14]$

With respect to tobacco consumption, Ortega-Ceballos and collaborators report that the highest rate of tobacco consumption occurs in the first year of the degree, and that this is progressively reduced as they advance through the school year, probably due to the awareness that is generated in the students as their academic training progresses. The increase in tobacco consumption corresponds to that indicated in the ENCODAT, where an increase in tobacco consumption is observed since 2015. Furthermore, specifically for the State of Mexico, the age of highest consumption is the population that has an age range of between 17 and 24 years of age, which also includes the average age of entry of students. [9] Studies conducted by Mazariegos and Barra share the average age of initiation, and as in our study there is no statistical significance in the consumption among men and women. Based on this analysis, it can be inferred that many of the new students smoke before entering the university. [16] [17]

ENCODAT 2017, had reported a stability in alcohol consumption in the population aged 18 to 65 years, compared to 2011 , however, in the last phase of evaluation of the survey, reported a significant increase (35-39\%). The behavior of the data in our study corresponds to that indicated in the survey, since it has statistical significance in the average of 
2016, with respect to 2017 [9], the latter being the year that reported the highest frequency of alcohol with respect to other generations of new entrants. Of the students surveyed, more than $90 \%$ reported having consumed alcohol, a figure that compares to the study conducted by Zambrano and collaborators, where the prevalence of consumption is above $90 \%$, both for public and private universities [18]. Many of the students enter university with a history of alcohol consumption; authors such as Puig and Alberto have reported an age of beginning alcohol consumption before coming of age $[18,19]$, which in Mexico corresponds to 18 years old, an age in which it is understood that students have a state of maturity that allows them to perform self-care to preserve their health. However, when considering the early age of consumption, the risk that the prevalence of consumption increases is greater, given that the population in our study has not yet begun to face the academic stress of their respective careers [20].

ENSANUT 2016, halfway through, reported a decrease in exercise among the Mexican population aged 20-69 years compared to the study conducted in 2012 (16.0\% to 14.4\%), and since then there has been no statistical significance in the frequency of activity among men and women (15.2\% vs. 13.7\%); however, an analysis of ENSANUT 2018 again reports an increase in the frequency of physical activity (16-29\%) compared to the 2016 study [21] [22]. The behavior of the national data is consistent with those obtained in the study, since as shown, the new students of the 2016 generation were those who reported a lower frequency of physical activity. However, when interviewing the 2017 generation, the frequency increased significantly, being the generation that had the highest frequency of the three interviewed.

Finally, of the four variables to be evaluated, cultural activity was the one with the lowest score in the three generations evaluated. This data corresponds to the results obtained in the National Survey of Cultural Consumption of Mexico 2012[23], which states that the population between 30 and 49 years of age had the highest rate of attendance at a cultural activity (cinema, theater, cultural centers, museums, newspaper library, etc.); with respect to the population between 18 and 29 years of age, the one that mostly attends cultural events is the one with basic education, that is to say, there is little participation from the university community[24]. It should be noted that in Mexico, data on cultural activity and consumption is not continuously updated in comparison with other surveys such as ENCODAT and ENSANUT. Low cultural consumption by university students has been reported for more than two decades. In the Survey of Cultural Consumption of University Students, it was reported that $60.5 \%$ of the students interviewed declared that they "never" or "almost never" go to the cultural offerings of public or private centers.

\section{Conclusion}

This research had as objective the analysis of 4 variables, to be able to make an initial diagnosis about the students' lifestyles (Physical and Cultural Act.) that promote a healthy life and two of the most common risk factors practiced in this population (alcohol and tobacco consumption). Since one of the commitments of the UNAM, and the service of PROSALUD, is to assess the health status of new students, as well as the identification of risk factors that may impact the student's health and academic performance. One of the pillars of PROSALUD's philosophy is prevention and the promotion of self-care, since unfortunately the Mexican population does not have a culture of prevention. This is reflected in the university population, which begins to take care of its health when there is a medical diagnosis that requires the use of second level health services; Therefore, the service is dedicated to planning health programs that help reduce the consumption of these harmful substances or their effect in preventing the start of their consumption during their school career. Likewise, cultural and physical activity is encouraged, which is more favored thanks to the wide range of activities offered by the university to its student enrollment, and it should be emphasized that the vast majority of these are free. This generational analysis, gives us an idea of how the student data behaves with respect to the national bases; it does not escape our analysis that it is required to work with more specifications and other components that are involved in the health of students. Therefore, in addition to continuing with the general diagnosis of new students, we will be relating variables in a more specific way and structuring specific health interventions for the attention of students, as well as the follow-up of students who require it, until the end of their student stay.

\section{Recommendations}

For this study we emphasize that we only worked with the population that attended the EMA, it is clear that there is an increase in the consumption of alcohol and tobacco in the university population, as indicated by the statistics of the National Survey of Addictions in Mexico, our recommendations to the universities are greater emphasis on health programs for the attention of university students, where primary care and prevention with a comprehensive approach is covered. As managed by PROSALUD, UNAM, FESI, where one of the pillars of the program is the prevention of chronic and infectious diseases, care in sexual and psychological health, and attention in the prevention and consumption of harmful substances; to guarantee students, a state of decent health that will allow them to reduce or avoid the consumption of harmful substances, as well as the opportunity to continue with their recreational activities. 


\section{Compliance with ethical standards}

\section{Acknowledgments}

Acknowledgments must be inserted here.

We thank the university community for the time it took to answer the instrument.

\section{Disclosure of conflict of interest}

No conflict of interest exists.

\section{Statement of informed consent}

In this study, informed consent was obtained from each of the students who participated in the study.

\section{References}

[1] Peña-de León A de la, Amezcua-Núñez JB, Hernández-Bonilla A, Peña-de León A de la, Amezcua-Núñez JB, Hernández-Bonilla A. La promoción de estilos de vida saludable aprovechando los espacios públicos. Horiz Sanit. diciembre de. 2017; 16(3): 201-10.

[2] Iglesias EB, Vázquez FL, Guadalupe LAO. Promoción de los estilos de vida saludables : ¿realidad o utopía? Rev Psicol. 1 de septiembre de. 1999; 17(2): 169-228.

[3] Estrés, Depresión Y Consumo De Alcohol En Estudiantes De Bachillerato De México: Diferencias Por Sexo Y Escuela | Request PDF [Internet]. [citado 7 de marzo de 2020].

[4] Giraldo Osorio A, Toro Rosero MY, Macías Ladino AM, Valencia Garcés CA, Palacio Rodríguez S. HEALTH PROMOTION AS A STRATEGY TO ENCOURAGE HEALTHY LIFE STYLES. Hacia Promoc Salud. julio de. 2010; 15(1): 128-43.

[5] Montoya LRG. Estilo de Vida Y Salud... [Internet]. Editorial Academica Espanola. 2011.

[6] Facmed_nov-dic-2016.pdf [Internet]. [citado 27 de diciembre de 2020]. Disponible en: https://www.pveu.unam.mx/informacion/medicina/facmed_nov-dic-2016.pdf

[7] Lara Y, Quiroga C, Jaramillo A, Bermeo M. Estilo de vida de estudiantes en primer semestre de odontología de una universidad privada, Cali 2016. Rev Odontológica Mex [Internet]. 16 de enero de 2019 [citado 7 de marzo de 2020]; 22(3).

[8] Población. Número de habitantes [Internet]. [citado 7 de marzo de 2020].

[9] Encuesta Nacional de Consumo de Drogas, Alcohol y Tabaco [Internet]. [citado 7 de marzo de 2020].

[10] Prevalencia del consumo cultural, del tiempo libre y de medios de comunicación, en estudiantes de ciencias de la salud en dos universidades latinoamericanas: Guadalajara y Guatemala. [Internet]. [citado 7 de marzo de 2020].

[11] Uso del tiempo y consumo cultural de los estudiantes universitarios [Internet]. [citado 7 de marzo de 2020].

[12] Más de 14 mil actividades exclusivas para alumnos [Internet]. Gaceta UNAM. 2019 [citado 7 de marzo de 2020].

[13] Toribio L. Jóvenes entran a la UNAM más grandes.

[14] Portal de Estadísticas Universitarias [Internet]. [citado 6 de junio de 2020].

[15] Ortega-Ceballos PA, Terrazas-Meraz MA, Arizmendi-Jaime ER, Tapia-Domínguez M, Ortega-Ceballos PA, Terrazas-Meraz MA, et al. Conocimientos, actitudes y factores asociados al consumo de tabaco en estudiantes universitarios de enfermería. Enferm Univ. junio de. 2018; 15(2): 159-71.

[16] Cheesman Mazariegos SS, Suárez Lugo N. Tabaquismo en estudiantes de medicina de la Universidad de San Carlos de Guatemala. Rev Cuba Salud Pública. marzo de. 2015; 41(1).

[17] Barra CL, Fernández PP, Granada GF, Ávila CP, Mallea MJ, Rodríguez MY. Diagnóstico del consumo de tabaco en estudiantes de pregrado de la Pontificia Universidad Católica de Valparaíso. Rev Médica Chile. octubre de. 2015; 143(10): 1343-50. 
[18] Puig-Nolasco A, Cortaza-Ramirez L, Cristina Pillon S. Consumo de alcohol entre estudiantes Mexicanos de medicina. Rev Lat Am Enfermagem. junio de. 2011; 19(spe): 714-21.

[19] Motivos y tipos de consumo de alcohol en estudiantes universitarios de enfermería | NURE Investigación. [citado 10 de junio de 2020];

[20] Valdez-Rodríguez BE, Rodríguez-Olivas MA, Hernández-Bernadett J. Características de Fumadores Universitarios. 2019;12.

[21] Encuesta Nacional de Salud y Nutrición - MC [Internet]. ENSANUT. [citado 16 de julio de 2020].

[22] Ensanut_2018_presentacion_resultados.pdf [Internet]. [citado 10 de junio de 2020].

[23] Encuesta Nacional de Consumo Cultural de México (ENCCUM) 2012 [Internet]. [citado 16 de julio de 2020].

[24] Alfonso Guzmán, Sergio Rommel, Usos del tiempo y consumo cultural de los estudiantes universitarios. Revista de la Educación Superior [Internet]. 2013; XLII (1)(165): 171-176. 